Research Journal of Applied Sciences, Engineering and Technology 5(9): 2734-2739, 2013

DOI:10.19026/rjaset.5.4799

ISSN: 2040-7459; e-ISSN: 2040-7467

(C) 2013 Maxwell Scientific Publication Corp.

\begin{tabular}{lll}
\hline Submitted: September 22, 2012 & Accepted: November 02, 2012 & Published: March 20, 2013
\end{tabular}

\title{
Research Article \\ A Comparative Study on the Adsorption and Desorption of Nitrogen and Phosphorus by Three Matrixes of Eco-River Channel
}

\author{
Yujia Song and Huiqing Liu \\ Department of Urban and Environment Sciences, Northeast Normal University, \\ Changchun 130024, P.R. China
}

\begin{abstract}
Eco-river channel building is an effective remediation technology for water body. Selecting appropriate matrix material to build eco-river channel can improve its purification capacity on the pollutants. In this paper, we conducted a comparative study on the adsorption capacity of gravel, sand and zeolite on nitrogen and phosphorus and made an initial analysis on its adsorption mechanism. The results show that, Freundlich isotherm equation can better describe the adsorption properties of those three materials, shown as follows: zeolite $>$ gravel $>$ sand. Thus, we should select gravel or zeolite with greater adsorption ability as matrix material to build eco-river channel, for it will not cause secondary pollution for water environment.
\end{abstract}

Keywords: Eco-river channel, natural materials, repair, secondary pollution

\section{INTRODUCTION}

In China, most of the lakes and rivers are in the eutrophic state. In general cases, the concentration of total phosphorus and inorganic nitrogen respectively up to $0.02 \mathrm{mg} / \mathrm{L}$ and $0.3 \mathrm{mg} / \mathrm{L}$ of water indicates that this river has been in eutrophic state. Scholars always focus on the links: control source-retention-conduit-repair and so on to control eutrophication (Chen, 2001). Therefore, to control transmission means, build ecological river and improve the self-purification ability of ecological environment by natural or artificial efforts is profitable for the removal of nitrogen and phosphorus and other pollutants (Liu and $\mathrm{Du}$ 2002; Mitsch and Jorgensen, 1989; Dong, 2003), thus controlling the progress of eutrophication (Kivaisi, 2001). The matrix of surface flow wetlands and the eco-materials in eco-river have something in common, so domestic researches on the adsorption properties of constructed wetland matrix on nitrogen and phosphorus are instructive for the selection of appropriate ecological materials to build the ecological river channel (Gopal, 1999).

Yuan et al. (2005) in Nanjing University have studied the purification performance of sand, zeolite, slag and other wetland matrixes on the phosphorus. The results show that zeolite is an artificial wetland matrix which can better remove phosphorus, due to its good permeability as well as the widely distributed feature, etc; sand is often regarded as the matrix of constructed wetland. North America, Europe and Australia all research the phosphorus removal capacity of constructed wetland matrix. New Zealand has studied the adsorption process of soil, slag, zeolite and other materials on the phosphorus. Norwegian has studied the adsorption capacity of clay minerals on phosphorus. British have studied the removal effect of limestone, gravel, zeolite and other materials on the phosphorus (Sakadevan, 1998; Zhu et al., 1997; Drizo et al., 1999; Arias et al., 2001).

In this study, we made comparative experiments on the adsorption of 3 different eco-matrixes-- gravel, sand and zeolite of eco-river channel on nitrogen and phosphorus, aiming to study its impact on the removal effect and mechanism of nitrogen and phosphorus, which is conductive for the materials selection as well as optimism and can also provide a theoretical support for the eco-river building in northern China.

\section{MATERIALS AND METHODS}

Research location: As the sole river which flows through territory of other countries, Yitong River has become the most important water source in Changchun City. It has the length of $342.5 \mathrm{~km}$ and the drainage area of $8440 \mathrm{~km}^{2}$. Besides, it belongs to seasonal rivers, which means its flow will change with the seasons and the amount of precipitation and even the local river may run dry in the dry season. The river has poor self-purification capacity, coupled with the domestic sewage, industrial wastewater as well as the agriculture wastewater, its water quality generally deteriorates, the structure and function of aquatic ecosystem also undergoes significant change, which all increases the pollution. The water quality data of

\footnotetext{
Corresponding Author: Yujia Song, Department of Urban and Environment Sciences, Northeast Normal University, Changchun 130024, P.R. China

This work is licensed under a Creative Commons Attribution 4.0 International License (URL: http://creativecommons.org/licenses/by/4.0/).
} 
Res. J. Appl. Sci. Eng. Technol., 5(9): 2734-2739, 2013

Table 1: Water quality data of Yitong River (2010)

\begin{tabular}{llll}
\hline & Water quality index & & \\
Sampling cross-section & Ammonia nitrogen $(\mathrm{mg} / \mathrm{L})$ & Total phosphorus(mg/L) & Total nitrogen(mg/L) \\
\hline 1 & 45.7 & 7.58 & 67.3 \\
2 & 11.6 & 1.82 & 28.5 \\
3 & 16.5 & 6.48 & 41.6 \\
\hline
\end{tabular}

Table 2: Physics-chemical characteristics of substrates used in experiments

\begin{tabular}{llll}
\hline Chemical property & Sand & Zeolite & Gravel \\
\hline $\mathrm{pH}$ & 7.11 & 7.82 & 7.23 \\
Specific surface area $\left(\mathrm{m}^{2} / \mathrm{g}\right)$ & 1.89 & 199.70 & 32.65 \\
Hydroxyl emission $(\mathrm{cmol} / \mathrm{kg})$ & 0.50 & 3.35 & 1.62 \\
Free iron oxide (\%) & 0.40 & 0.42 & 0.41 \\
Colloidal iron oxide (\%) & 0.14 & 0.21 & 0.15 \\
Free alumina (\%) & 0.088 & 0.18 & 0.09 \\
Colloidal alumina (\%) & 0.033 & 0.11 & 0.045 \\
Water-soluble calcium (\%) & 0.016 & 0.027 & 0.018 \\
\hline
\end{tabular}

Yitong River in 2010 (Table 1) shows that Yitong River has been in the state of serious eutrophication.

Experimental materials: The sand and gravel in this paper was selected from the riverbed of Yitong River; zeolite was purchased from Zhejiang Shenshi quarry Ltd. The main mineral composition of these three materials has been analyzed by X-ray diffraction: the main mineral of sand is quartz, while the main mineral of zeolite is mordenite.

Determination of nitrogen and phosphorus: The nitrogen was determined by the per sulfate oxidationUV spectrophotometer, while the ammonia nitrogen was determined by Nessler colorimetric method. Phosphorus content was determined by antimolybdenum antimony calorimetric; the full dose of mineral matrix was determined by X-ray fluorescence analysis. Matrix mineral content and some of chemical and physical properties are as shown in Table 2 .

The experimental method of the isothermal adsorption capacity of 3 eco-river matrixes on nitrogen and phosphorus: Respectively weigh gravel, sand and zeolite of $1 \mathrm{~g}$ (ground through 100 mesh sieve) and then place it in $50 \mathrm{~mL}$ centrifuge tube, adding $30 \mathrm{~mL}$ ammonium sulfate with different concentrations. Set three parallel samples for each concentration. Place them in the constant temperature shaker with the temperature $21^{\circ} \mathrm{C}(200 \mathrm{rpm})$ and shake. Take them out after $72 \mathrm{~h}$ and place in the centrifuge of $2000 \mathrm{rpm}$ for $10 \mathrm{~min}$. Take the supernatant fluid and determine their total nitrogen concentration. The difference between the determined concentration and the initial concentration is thought to be adsorbed by eco-materials. Meanwhile, in accordance with changes in their concentration it is also necessary to calculate the amount of adsorbed nitrogen, take the average and then draw the isothermal adsorption curve of nitrogen.

Accurately weigh the above matrix $1 \mathrm{~g}$ for 3 copies (parallel experiment) and respectively place them in the $50 \mathrm{~mL}$ plastic centrifuge tube. After adding the $30 \mathrm{~mL}$ standard $\mathrm{KH}_{2} \mathrm{PO}_{4}$ solution with different phosphorus concentration prepared by the $0.02 \mathrm{~mol} / \mathrm{LKCl}$ solution (recorded as P), place them in the constant temperature shaker with the rotate speed of $180 \sim 190 \mathrm{r} / \mathrm{min}$. After shaking them for $72 \mathrm{~h}$ at the temperature of $25^{\circ} \mathrm{C}$, conduct centrifugation and take the supernatant fluid to determine the phosphorus concentrations. Then according to the concentration changes, calculate the amount of adsorbed phosphorus, take the average and then draw the isothermal adsorption curve of phosphorus.

Experiment on the resolution of nitrogen and phosphorus after the absorption of the 3 eco-river matrixes reaches saturation: Take 3 copies of $1 \mathrm{~g}$ above matrix whose absorption of nitrogen and phosphorus has reached saturation (parallel experiments) and places them in plastic centrifuge tubes. Add $0.02 \mathrm{~mol} / \mathrm{LKCl}$ solution $25 \mathrm{~mL}$ and then place it in the constant temperature shaker with the rotate speed of $180 \sim 190 \mathrm{r} / \mathrm{min}$. After shaking it for 72 $\mathrm{h}$ at the temperature of $25^{\circ} \mathrm{C}$, conduct centrifugation and take the supernatant fluid to determine the phosphorus concentration and nitrogen concentration. Then calculate the amount of desorption nitrogen, take the average and draw the isothermal adsorption curve of nitrogen and phosphorus.

\section{RESULTS AND DISCUSSION}

Analysis on the results of nitrogen and phosphorus absorbed by 3 eco-river substrates: According to absorption of ammonia nitrogen and phosphate by gravel, sand and zeolite in nitrogen and phosphorus balance solution of different concentrations, we respectively draw the adsorption curves shown in Fig. 1 and 2.

For surface adsorption phenomenon of solid under constant temperature, the Freundlich and Langmuir are commonly used to represent relations between the surface adsorption of solid and the equilibrium concentration of solute in media.

In the derivation of Langmuir, supposing that there is no interaction between adsorbed molecules, which means the adsorption layer is ideal and immediately shows the formation of saturated monolayer. However, the adsorption process comes from the combined effect of solute and absorbent and it is impossible to be complete uniform on solid surface, so adsorption phase is difficult to be entirely satisfactory. Therefore, the Langmuir equation has the nature of empirical formula. Langmuir equation is expressed as follows: 


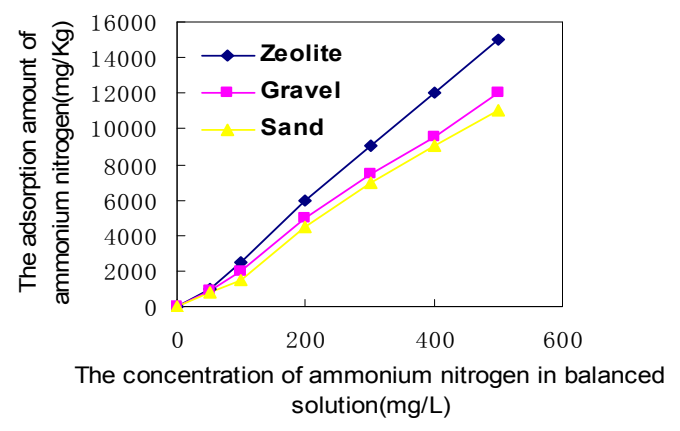

Fig. 1: Nitrogen adsorption of gravel, sand and zeolite in ammonia solution

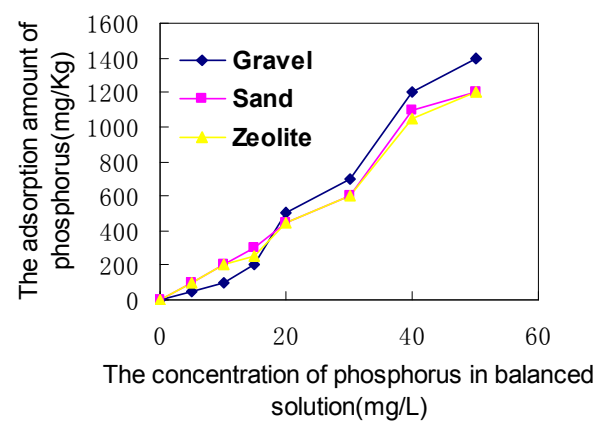

Fig. 2: Phosphorus adsorption of gravel, sand and zeolite in monopotassium phosphate solution

$$
c / x=1 /\left(k_{1} k_{2}\right)+c / k_{1}
$$

In the formula, $\mathrm{K}_{1}$ and $\mathrm{K}_{2}$ are constants. $\mathrm{K}_{1}$ represents the maximum $\mathrm{P}$ adsorption capacity or the maximum $\mathrm{N}$ adsorption capacity of Langmuir, while $\mathrm{K}_{2}$ is associated with the binding energy. The maximum adsorption capacity of Langmuir can be obtained by the coordinate $\mathrm{C}$ and the slope $\mathrm{C} / \mathrm{X}$.

The Freundlich equation is often used for asymmetrical surface of solid and its expression is usually expressed as follows:

$$
x=k \cdot \sqrt[n]{c}(\mathrm{n}>1)
$$

In the formula, $\mathrm{K}$ and $\mathrm{n}$ are constants. The constant $\mathrm{K}$ can be regarded as the adsorption index of phosphorus or nitrogen by equilibrium phosphorus or nitrogen solution per unit, which can provide ability associated with the balanced amount and adsorption of the phosphorus and nitrogen matrix. The equation can be rewritten as:

$$
\operatorname{In}=\operatorname{Ink}+\operatorname{Inc} / n
$$

In the formula, $\ln \mathrm{K}$ is the intercept and the $1 / \mathrm{n}$ is the slope; $\ln \mathrm{X}$ and $\ln \mathrm{C}$ form a linear relationship and constants $\mathrm{K}$ and $\mathrm{n}$ are obtained from it. According to the adsorption of ammonia nitrogen and phosphate by gravel, sand and zeolite in different equilibrium concentration, we calculate the relevant parameters of isothermal curve equation shown in Table 3 and 4.

It can be seen from Fig. 1 and 2 that the adsorption curves of gravel, sand and zeolite on nitrogen are in line with the "C"-type isotherm (Constant partition type) in the Giles classification of isotherms. Isotherm is a straight line which indicates that the distribution of ammonian in the solution of the surface of adsorption material is constant. This kind of isotherm may appear at the adsorption of some materials on the polymer composed by crystallization zone and amorphous zone. Its mechanism may be that first the adsorpate ammonia is adsorbed in the larger hole of amorphous zone and then due to the effect of adsorption, other parts expand and form the new adsorption potential, finally the new adsorption continues to occur until it cannot pass through the crystallization zone, resulting in the termination of adsorption. The adsorption of gravel, sand and zeolite on $\mathrm{P}$ is in line with the "S"-type isotherm in Giles classification of isotherm. The initial part of the isotherm has a smaller slope and convexes to the concentration axis. When there appears a strong competitive adsorption of solvent and the solute is adsorbed on the solid surface with its sole end nearly perpendicular to the surface, this kind of isotherm may appear. When the equilibrium concentration increases, the isotherm has a correspondingly sharp increase, which is because the absorbed phosphate has an attractive effect on the phosphate in the liquid.

According to different reasons that cause adsorption, absorbability of eco-materials can be divided into three categories, that is, physical adsorption, chemical adsorption and ion exchange (Cheng, 1995). Physical adsorption refers to adsorption generated by the attraction between molecules of adsorbent and adsorpate and adsorption produced by the hydrogen bond is also part of physical adsorption. Chemical adsorption refers to absorption generated by chemical bond force between adsorbent and adsorb ate. Anionic polymers can be adsorbed onto the surface of the eco-materials by chemical bonds and the adsorption methods have the following two forms: first, crystals of eco-materials are with positive charge and anionic groups can be adsorbed onto the side of eco-materials by electrostatic attraction. Second, when there is neutral electrolyte in the media, inorganic cations can play a role of "bridge" between ecological materials and anionic polymers, which makes the high polymer adsorped on the surface of eco-materials. Sometimes eco-materials are with unsaturated charge and according to neutral principles; there must be equal number of different ion adsorption on the surface of the material to achieve electrical balance. Usually, ions adsorbed on the surface of ecological materials can exchange with the same number of ions in the solution, which is the ion exchange adsorption. The most 
Res. J. Appl. Sci. Eng. Technol., 5(9): 2734-2739, 2013

Table 3: The Freundlich and Langmuir adsorption isotherms of ammonium nitrogen in substrates in experiments

\begin{tabular}{|c|c|c|c|c|c|c|}
\hline \multirow[b]{2}{*}{ Matrix } & \multicolumn{3}{|c|}{ Freundlich equation } & \multicolumn{3}{|c|}{ Langmuir equation } \\
\hline & $\mathrm{K}$ & $\mathrm{n}$ & $\mathrm{R}^{2}$ & $\mathrm{~K}_{1} \mathrm{~K}_{2}$ & $\mathrm{~K}_{1}(\mathrm{mg} / \mathrm{Kg})$ & $\mathrm{R}^{2}$ \\
\hline$\overline{\text { Gravel }}$ & 24.4 & 1.04 & 0.935 & 18415.29 & 423.34 & 0.278 \\
\hline Sand & 24.2 & 1.02 & 0.896 & 14927.48 & 340.81 & 0.171 \\
\hline Zeolite & 41.2 & 0.85 & 0.927 & 80239.26 & 1840.35 & 0.457 \\
\hline
\end{tabular}

Table 4: The Freundlich and Langmuir adsorption isotherms of phosphorus in substrates in experiments

\begin{tabular}{|c|c|c|c|c|c|c|}
\hline \multirow[b]{2}{*}{ Matrix } & \multicolumn{3}{|c|}{ Freundlich equation } & \multicolumn{3}{|c|}{ Langmuir equation } \\
\hline & $\mathrm{K}$ & $\mathrm{n}$ & $\mathrm{R}^{2}$ & $\mathrm{~K}_{1} \mathrm{~K}_{2}$ & $\mathrm{~K}_{1}(\mathrm{mg} / \mathrm{Kg})$ & $\mathrm{R}^{2}$ \\
\hline$\overline{\text { Gravel }}$ & 4.39 & 0.65 & 0.972 & 9938.86 & 230.6 & 0.593 \\
\hline Sand & 19.26 & 0.94 & 0.913 & 35640.06 & 813.7 & 0.642 \\
\hline Zeolite & 15.65 & 0.89 & 0.965 & 13171.56 & 302.1 & 0.794 \\
\hline
\end{tabular}

Table 5: The ratio of desorption and maximum adsorption of nitrogen in substrates saturated with nitrogen

\begin{tabular}{|c|c|c|c|}
\hline Substrate & Gravel & Sand & Zeolite \\
\hline Theoretical maximum adsorption $(\mathrm{mg} / \mathrm{kg})$ & 423.34 & 340.81 & 1840.35 \\
\hline Maximum desorption (mg/kg) & 56.81 & 63.70 & 63.68 \\
\hline Ratio of desorption(\%) & 13.42 & 18.69 & 3.46 \\
\hline Substrate & Gravel & Sand & Zeolite \\
\hline Theoretical maximum adsorption $(\mathrm{mg} / \mathrm{kg})$ & 230.6 & 813.7 & 302.1 \\
\hline Maximum desorption (mg/kg) & 22.44 & 108.06 & 8.73 \\
\hline Ratio of desorption (\%) & 9.73 & 13.28 & 2.89 \\
\hline
\end{tabular}

common exchanging ions that combine with ecological materials are $\mathrm{Ca}^{2+}, \mathrm{Mg}^{2+}, \mathrm{H}^{+}, \mathrm{K}^{+}, \mathrm{NH}_{4}^{+}, \mathrm{Al}^{3+}, \mathrm{SO}_{4}^{2-}$, $\mathrm{Cl}{ }^{-}, \mathrm{NO}_{3}^{-}$and other anions. According to different electrical properties of exchanging ions, ion exchange adsorption can be divided into cation exchange adsorption and anion-exchange adsorption.

Many studies have shown that the selfphosphorus-purification ability of constructed wetland matrix is apt to be influenced by its own composition and physical and chemical properties (Yuan and Lakulich, 1994; Lu et al., 2003; Gao et al., 2001; Gray and Schwab, 1993). The theoretic saturated extent of adsorption of phosphorus has a highly significant positive correlation to the content of hydroxide radical resolution, total $\mathrm{Ca}$, soluble $\mathrm{Ca}$, free iron oxide, colloidal iron oxide, free alumina and colloidal alumina of substrate (Bubba et al., 2003; Chen et al., 1999). This indicates that the main mechanism of substrate's adsorption on phosphorus is the chemical mechanism, which has a weaker impact on the phosphorus than surface. Besides, substrate's adsorption on phosphorus is resulted by composite factors (Bastin et al., 1999; Chueng and Venkitachalam, 2000; Ann et al., 2000).

It can be seen from Table 3 and 4 that when the concentration of $P$ in equilibrium solution is $0-50 \mathrm{mg} / \mathrm{L}$ and the concentration of ammonia in equilibrium solution is in the range of $0-500 \mathrm{mg} / \mathrm{L}$, compared with Langmuir equation, Freundlich equation can better describe the adsorption law of 3 eco-logical materialsgravel, sand and zeolite on nitrogen and phosphorus. Freundlich equation is an empirical equation, but its adsorption coefficient is closely related to the saturation concentration, thus compared with the constant of constraint capacity in Langmuir equation, it conforms to the practical situation better. The $\mathrm{k}$ value of the Freundlich equation indicates that the saturated adsorption capacity of 3 eco-materials on ammonia adsorption is followed by zeolite $>$ gravel $>$ sand, which is consistent with experimental results. While the adsorption capacity on phosphate is followed by sand $>$ zeolite $>$ gravel, which is different with the experimental fact that zeolite test $>$ gravel $>$ sand. There may be two reasons: First is caused by the error generated in the experiment. Second, the absorbent material has ground through 100 mesh sieve, thus its physical properties and crystal structure has changed, which means particle adsorption has transformed into a colloidal adsorption.

Analysis of desorption of nitrogen and phosphorus by three kinds of ecological river substrates: Nitrogen and phosphorus desorption test after phosphorus is saturated in substrate shows that the nitrogen and phosphorus desorption reaches equilibrium in about 2 to $4 \mathrm{~h}$ and the maximum adsorption capacity is shown in Table 5 and 6 .

Nitrogen and phosphorus adsorbed by sand have the maximum desorption rate, followed by gravel and then zeolite. Considering the saturated adsorption and largest desorption capacity of sand, its higher desorption rate, but the desorption of phosphorus reach equilibrium in a very short period of time, we can carry out desorption by using water of low or no phosphorus content immediately after it is saturated and then collect the desorption solution for processing or strengthen the management of vegetation systems by increasing the purification ability of vegetation system to delay the time it reaches saturation. Usually, the secondary 
pollution of phosphorus can be avoided. Similarly, under normal circumstances, if zeolite is properly handled, it will not result in secondary pollution of phosphorus.

Early in 1990s, Japanese Professor Ryoichi Yamamoto first proposed the concept of "ecomaterials" in his research (Yamamoto, 1994), which was then responded positively by workers in the world. Eco-material should have three kinds of characteristics: First, excellent performance, known as advance of materials; the second is that in the preparation, distribution, use and disposal of materials and the entire process must maintain the coordination with the global environment; third, the senses of the nature of materials. It is required to feel comfortable and users are willing to adopt it, which is called comfort of materials (Zuo and Nye, 2003).

The natural ecological materials mainly refers to some materials produced in natural state, such as natural rocks, minerals, natural wood, all kinds of biomass, etc and in the use of these materials, we do not need to consume more energy, without too much pollution produced when they are done. Because of its excellent properties, natural ecological material is the best choice to build eco-bed. Both bio-film which is significant for the repair of water ecology and large aquatic plants grow on these eco-bed material $(\mathrm{Wu}$, 2004). These factors have a good facilitating role of water purification. According to the actual situation of eco-bed construction, this study selected three kinds of natural ecological materials for building river way, that is, gravel, sand and zeolite.

As an artificial wetland substrate, sand often seems to have inadequate purification ability, but its permeability is good, not easy to plug. If you add substrate that has relatively strong adsorption ability of nitrogen and phosphorus, or enhance management of wetland vegetation system, sand substrate is still the first choice of building ecological river channel. Zeolite does well in adsorption of nitrogen and its permeability is also very good. Because there are many types of zeolite and their capacity of adsorbing phosphorus varies greatly with each other, we can choose zeolite with better ability of adsorption as the wetland substrate, for desorping nitrogen and phosphorus.

According to the specific circumstances of Yitong River, we can mix zeolite with a certain percentage combined with local river sand in building ecological river channel or substrate of ecological treatment facility for river sand filter, which can enhance the adsorption ability of nitrogen and phosphorus, but also increase the porosity of the substrate, reduce congestion and thus contributing to the spread of oxygen. This is conducive to implantation of plant and microbial startup, which can enhance the cleaning effect of nitrogen and phosphorus and play a positive role in controlling eutrophication.

\section{CONCLUSION}

We conducted a comparative study on the adsorption capacity of gravel, sand and zeolite on nitrogen and phosphorus and made an initial analysis on its adsorption mechanism. The results show that, Freundlich isotherm equation can better describe the adsorption properties of those three materials, shown as follows: zeolite $>$ gravel $>$ sand. This indicates that the main mechanism of substrate's adsorption on phosphorus and nitrogen is the chemical mechanism, which has a weaker impact on the phosphorus than surface. Besides, substrate's adsorption on phosphorus is resulted by composite factors.

Phosphorus and nitrogen desorption test after phosphorus and nitrogen is saturated in substrate shows that Nitrogen and phosphorus adsorbed by sand have the maximum desorption rate, followed by gravel and then zeolite, usually, the secondary pollution of phosphorus and nitrogen can be avoided.

Gravel, sand and zeolite all can absorb nitrogen and phosphorus in water. In the artificial strengthening process of adsorption under constant temperature, Freundlich equation can better describe the adsorption law of nitrogen and phosphorus these three kinds of ecological materials than the Langmuir equation, which has a positive guidance for further study of engineering use. To use gravel or zeolite which is of better adsorption ability as the substrate of ecological river course is an effective measure to build ecological river channel. The forms of nitrogen in the environment are complex and varied and their adsorption law requires further study.

\section{ACKNOWLEDGMENT}

It is a project support by the National Natural Science Foundation of China (40871005).

\section{REFERENCES}

Ann, Y., K.R. Reddy and J.J. Delfino, 2000. Influence of chemical amendments on phosphorus immobilization in soil from a constructed wetland [J]. Ecol. Eng., 14(1-2): 157-167.

Arias, C.A., M.D. Bubba and H. Brix, 2001. Phosphorous removal by sands for use as media in subsurface flow constructed reed beds [J]. Water Res., 35(7): 1159-1168.

Bastin, O., F. Janssen and J. Dufay, 1999. Phosphorus removal by synthetic iron oxide gypsum compound [J]. Ecologic. Eng., 12(3-4): 339-351.

Bubba, M.D., C.A. Arias and H. Brix, 2003. Phosphorus adsorption maximum of sands for use as media in subsurface flow constructed reed beds as measured by the Langmuir isotherm [J]. Water Res., 37(14): 3340-3390. 
Chen, H.S., 2001. Restoration project of the ecosystem in Tai lake $[\mathrm{J}]$. Resour. Enuiron. Yang. Basin, 10(3): 173-178.

Chen, B.Q., X. Wang and C.Q. Yin, 1999. The role of soils in waste water treatment in a simulated constructed wetland [J]. Urban Environ. Urban Ecol., 12(1): 19-22.

Cheng, H.X., 1995. Surface Physical Chemistry [M]. Science and Technology Literature Press, Beijing.

Chueng, K.C. and T.H Venkitachalam, 2000. Improving phosphate removal of sand infiltration system using alkaline fly ash [J]. Chemosphere, 41(1-2): 243-249.

Dong, Z.R., 2003. Theoretical framework for ecohydraulics [J]. J. Hydraul. Eng., 28(1): 1-6.

Drizo, A., C.A. Frost and J. Grace, 1999. Physicochemical screening of phosphere removing substrates for use in constructed wetland systems [J]. Water Res., 33(6): 3595-3602.

Gao, C., T.L. Zhang and W.D. Wu, 2001. Phosphorus sorption and desorption of agricultural soils under different land uses [J]. Environ. Sci., 22(7): 67-72.

Gopal, B., 1999. Natural and constructed wetlands for waste water treatment: Potential and problems $[\mathrm{J}]$. Water Sci. Technol., 40(3): 27-35.

Gray, C.A. and A.P. Schwab, 1993. Phosphorus fixing ability of high $\mathrm{pH}$, high calcium coal combustion waste materials [J]. Water Air Soil Poll., 69(6): 309-320.

Kivaisi, A.K., 2001. The potential for constructed wetlands for wastewater treatment and reuse in developing country [J]. Ecol. Eng., 16(2): 545-560.

Liu, X. and G.X. Du, 2002. Phytoplankton and the controlling of eutrophication of water body $[\mathrm{J}]$. J. Cap. Norm. Unive., 23(12): 56-63.
Lu, Y., Z.T. Gong and G.L. Zhang, 2003. Phosphorus forms and adsorption-desorption characteristics of urban soils in Nanjing [J]. Chinese J. Soil Sci., 34(2): 40-43.

Mitsch, W.J. and S.E. Jorgensen, 1989. Ecological Engineering. An Introduction to Ecotechnology. John Wiley and Sons, New York, pp: 472.

Sakadevan, K., 1998. Phosphate adsorption characteristics of soils, slag and zealot to be used as substrates in constructed wetland system $[\mathrm{J}]$. Water Res., 32(2): 393-399.

Wu, P.X., 2004. Clay Mineral Materials and Environmental Remediation [M]. Chemical Industry Press, Beijing.

Yamamoto, R., 1994. Eco-materials [M]. Chinese Chemical Industry Press, Beijing.

Yuan, G. and L.M. Lakulich, 1994. Phosphate adsorption in relationship to extractable and aluminum in spodosols [J]. Soil Sci. Soc. Am. J., 58(5): 343-346.

Yuan, D.H., L.J. Jing, S.X. Gao, D.Q. Yin and L.S. Wang, 2005. Analysis on the removal efficiency of phosphorus in some substrates used in constructed wetland systems [J]. Environ. Sci., 26(1): 51-55.

Zhu, T., P.D. Janssen and T. Melham, 1997. Phosphate adsorption and chemical characteristics of light weight aggregates-potential filter media in treatment wetlands [J]. Water Sci. Technol., 35(5): 103-108.

Zuo, T.Y. and Z.R. Nye, 2003. The Basis of Environmental Materials [M]. Science Press, Beijing. 